\title{
FILOSOFIA BRASILEIRA E PENSAMENTO DESCOLONIAL
}

\author{
BRAZILIAN PHILOSOPHY AND DECOLONIAL THOUGHT
}

Paulo Margutti*

\begin{abstract}
RESUMO
Esse artigo constitui uma introdução ao pensamento descolonial aplicado à situação da filosofia tal como praticada no Brasil, principalmente nas instituições ligadas à ANPOF. Depois de uma descrição dessa situação, é feita uma análise da mesma com base em algumas técnicas inspiradas nas ideias de Walter Mignolo.
\end{abstract}

PALAVRAS-CHAVE: Filosofia brasileira. Filosofia no Brasil. Pensamento descolonial.

\section{ABSTRACT}

This paper constitutes an introduction to decolonial thought as applied to the situation of philosophy as practiced in Brazil, mainly in the institutions linked to ANPOF. After describing the situation, an analysis of it is made on the basis of some techniques inspired by Walter Mignolo's ideas.

KEYWORDS: Brazilian philosophy. Philosophy in Brazil. Decolonial thought.

\section{INTRODUÇÃO}

De uns tempos para cá, os estudiosos de filosofia têm revelado uma grande curiosidade a respeito do pensamento descolonial e suas possíveis aplicações ao caso brasileiro. Essa nova forma de pensamento constitui um fenômeno relativamente recente, que surgiu sobretudo a partir da atuação de determinados pensadores latino-americanos nos EUA. Dentre eles, podemos destacar, p. ex., Walter Mignolo, Susana Nuccetelli, Ofelia Schutte, Jorge Gracia e Eduardo Mendieta. Esses autores e vários outros trouxeram muitas contribuições importantes para o pensamento descolonial e seus textos constituem leituras obrigatórias para que possamos chegar a um conhecimento adequado da filosofia descolonial e seus instrumentos de trabalho. ${ }^{1}$

O presente texto pretende dar um exemplo desse novo tipo de análise aplicado a alguns aspectos da situação da filosofia no Brasil. As etapas que seguiremos para cumprir nosso objetivo serão as seguintes. Em primeiro lugar, faremos uma breve apresentação da

\footnotetext{
* Doutor em Filosofia pela Un. de Edinburgh. Professor titular aposentado da UFMG. Professor titular da Faculdade Jesuíta de Filosofia e Teologia (FAJE/MG). E-mail: paulomargutti@terra.com.br.

${ }^{1}$ Ver, p. ex., Mendieta (2003) - Moraña; Dussel; Jáuregui (2008) - Rodríguez (2001).
} 
situação da prática filosófica atual no país e das causas que possivelmente levaram a ela, principalmente no caso das entidades ligadas à ANPOF. Em segundo lugar, procuraremos mostrar um exemplo de aplicação da via do pensamento descolonial ao nosso caso e sugerir o que poderia ser feito para superar essa situação. A nossa expectativa é a de que isso possa constituir um estímulo para que os leitores desenvolvam leituras posteriores e exercitem eles próprios o pensamento descolonial.

\section{A SITUAÇÃO DA PRÁTICA FILOSÓFICA NO PAÍS E SUAS POSSÍVEIS CAUSAS}

Para entender a situação em que nos encontramos em termos de prática filosófica no país, convém que nos lembremos das nossas origens coloniais e da tradição ibérica que nos influencia até hoje. Conforme mostramos no primeiro volume de nossa História da filosofia do Brasil (1500-1822), essa tradição se caracterizou, em Portugal, pela existência de três tendências filosóficas. A primeira delas é o sanchismo, que recebeu esse nome porque seu iniciador foi o pensador cético Francisco Sanches, que se inspirou em alguns aspectos da filosofia socrática. Essa tendência é caracterizada pela ênfase na vida prática, pela postura cética em relação à metafísica e pela ausência de elaborações teóricas. Pelo fato de não possuir espírito sistemático, ela se manifesta não apenas em textos filosóficos, mas também em obras literárias contendo intuições filosóficas. A segunda tendência é o fonsequismo, que recebeu esse nome porque seu iniciador foi o pensador Pedro da Fonseca, grande comentador de Aristóteles. Essa tendência é marcada pela ênfase no comentário exegético e pela ausência de elaborações pessoais. O espírito sistemático está presente aqui, mas prejudicado pela ausência de elaborações originais. A terceira tendência é a dos estrangeirados, ou seja, dos pensadores que, geralmente ocupando cargos diplomáticos, tiveram a oportunidade de viver em outras culturas, comparando-as com a portuguesa e percebendo o atraso dessa última. Seu iniciador foi Jacob de Castro Sarmento, influenciado pelos trabalhos de Newton. Essa tendência se caracteriza pela ênfase no pensamento crítico e reformista, que leva à produção de perspectivas pessoais e originais.

Essas três tendências foram por nós observadas durante a pesquisa que levou à redação do primeiro volume da nossa História da filosofia do Brasil (1500-1822). Os pensadores portugueses da época não tinham consciência dessa tripartição nem do seu enquadramento em uma dessas tendências. Desse modo, os sanchistas não eram necessariamente seguidores de 
Sanches, embora partilhassem com ele as características acima apontadas, sob a forma de uma visão de mundo comum. O mesmo vale para os fonsequistas e os estrangeirados.

No Brasil, que foi colônia de Portugal, ainda há traços dessas três tendências nos dias de hoje. Em nossa situação atual, o sanchismo é em geral representado pelo literato-filósofo, ou seja, pelo escritor que, apesar de produzir uma obra literária, inclui nela intuições filosóficas pessoais, muitas vezes originais e sempre relevantes para a compreensão de nossa maneira de ver o mundo. Como exemplos de literatos-filósofos, podemos citar Machado de Assis e Clarice Lispector.

O fonsequismo atual é representado pela maioria dos autores ligados à comunidade filosófica acadêmica do país, marcada pelo comentário de pensadores estrangeiros, sem buscar elaborações pessoais. É um fato curioso que esses autores brasileiros, em sua maioria, apesar de terem frequentado ou estudado em universidades estrangeiras, retornaram ao Brasil não como os antigos estrangeirados lusitanos, mas sim como comentadores especializados. Eles são suficientemente conhecidos em nossas universidades para que seja necessário mencionar nomes aqui. Essa ênfase na exegese pode ser explicada através da maneira pela qual se ensina a filosofia entre nós, principalmente nos casos das instituições ligadas à ANPOF e à Sociedade Brasileira de Filosofia. O ensino da filosofia no Instituto Rio Branco constituía uma honrosa exceção a esse quadro, mas atualmente deixou de lado a pedagogia marcada pelo estímulo à reflexão pessoal voltada para a realidade brasileira. Isso nos coloca numa situação pouco recomendável, em que os estudantes de filosofia são em geral formados para comentar textos clássicos, sem qualquer estímulo à reflexão pessoal e independente. É verdade que, no caso das instituições ligadas à Sociedade Brasileira de Filosofia, os estudantes são ao menos estimulados a se interessarem por autores brasileiros, enquanto que, no caso das instituições ligadas à ANPOF, esse estímulo é praticamente inexistente. Mas nos dois casos predomina a exegese de textos.

O estrangeirado atual é em geral representado pelo diplomata-filósofo, ou seja, por aquele autor que foi educado dentro dos antigos padrões do Instituto Rio Branco, que exigia a aplicação da filosofia à situação brasileira, através de elaborações pessoais. Como exemplo de autores dessa tendência, podemos citar Mário Vieira de Mello, José Oswaldo Meira Penna e José Guilherme Merquior, entre outros. Infelizmente, como já observamos, o ensino de filosofia no Instituto Rio Branco sofreu alterações e não faz mais a exigência acima, o que certamente significará uma perda para a intelectualidade brasileira. 
O quadro acima admite exceções, pois há também entre nós pensadores que não se enquadram adequadamente em nenhum dos grupos acima e que contribuíram com elaborações pessoais relativamente originais, como, p. ex., entre outros, Farias Brito, Roque Spencer Maciel de Barros, Vicente Ferreira da Silva, Álvaro Vieira Pinto e Roberto Mangabeira Unger.

Fato digno de nota, porém, é que os pensadores relevantes, em todos os grupos mencionados, permanecem de algum modo invisíveis para a parte mais prestigiada da comunidade filosófica brasileira, representada pelas instituições ligadas à ANPOF, de onde provêm inclusive a maioria dos pesquisadores altamente qualificados que contribuem para as atividades de avaliação da CAPES e para a distribuição de bolsas do CNPq. Através dessa atuação, estamos no momento não apenas praticando uma filosofia desligada da realidade brasileira, mas também produzindo uma autêntica comunidade de desconversação, num sentido oposto ao oferecido por Rorty. Por motivos de espaço, concentraremos nossa atenção, a partir desse ponto, na prática filosófica predominante na área de influência da ANPOF.

Aqui, o ensino de filosofia nos cursos de graduação é caracterizado pela ênfase nos pensadores europeus e norte-americanos, com pouco interesse pelo que se faz no país nesse domínio. Como se não bastasse isso, os autores estudados pertencem sobretudo aos períodos da Filosofia Grega e da Filosofia Moderna, com pouca atenção concedida à Filosofia Contemporânea, desviando o interesse do aluno em relação ao estudo do momento atual e suas implicações filosóficas. Isso tudo é feito com base na justificativa de que, para se obter uma boa formação filosófica, é necessário conhecer os textos clássicos. Esse conhecimento, evidentemente, é necessário, mas não pode ser o único objetivo de um curso de graduação em filosofia, pois, nesse caso, estaremos apenas desenvolvendo as habilidades exegéticas do aluno. A contrapartida é o desestímulo à elaboração de propostas pessoais. O aluno que tenta alguma coisa nesse sentido é geralmente criticado por praticar o famigerado achismo. $\mathrm{O}$ mecanismo é o seguinte: o aluno, genuinamente motivado por um dos temas debatidos durante a aula, oferece espontaneamente uma proposta pessoal de solução ao problema filosófico envolvido, dizendo eu acho que...; seu professor o vê como um jovem intelectualmente imaturo que está se atrevendo a oferecer alguma hipótese mirabolante sobre o problema discutido e lhe responde que, como aluno, não tem de achar coisa alguma e sim concentrar-se na compreensão do texto do autor clássico que levantou o problema. Com isso, o aluno vê castrada qualquer iniciativa de reflexão autônoma e, ao mesmo tempo, recebe um forte estímulo para se tornar um exegeta. 
Essa pedagogia equivocada encontra um reforço nos cursos de mestrado em filosofia. Aqui, continua a ênfase nas filosofias europeia e norte-americana, com pouco interesse pela filosofia praticada no país. Essa última é considerada por muitos como inexistente. O resultado disso é, por um lado, o fortalecimento do desestímulo à reflexão pessoal, uma vez que a dissertação de mestrado não precisa ser original, e, por outro, o aprimoramento das habilidades exegéticas do aluno, sob o pretexto de que isso é exigido para que ele tenha uma formação adequada do seu espírito crítico.

O caso dos cursos de doutorado em filosofia é mais complicado ainda. Com efeito, depois de anos de estudo incentivando a exegese de textos, o aluno encontra-se subitamente diante da exigência de produzir um trabalho original, demandando uma reflexão autônoma que ele nunca praticou. A exigência de originalidade em nossos cursos de dourado encontrase na contramão do que até então foi cobrado nos cursos de graduação e mestrado. Como o doutorando não está preparado para desenvolver o tipo de reflexão que se espera dele, os nossos cursos de pós-graduação adotaram uma solução paliativa para esse problema. Supondo que a tese de doutorado tenha três capítulos, os dois primeiros ainda podem ser de caráter exegético, a título de preparação do terreno para a tão esperada proposta pessoal. Esta fica reservada somente para o último capítulo e não precisa ser muito original: basta que dê a impressão de que alguma inovação foi feita para que a banca examinadora aprove a tese.

Esse quadro é um pouco diferente quando o doutorado foi realizado no exterior. Nesse caso, as teses costumam apresentar um pouco mais de originalidade, mas em geral envolvem no máximo alguma inovação na exegese de autores clássicos. Afinal de contas, a maioria dos doutorandos nessa situação receberam a sua formação no Brasil, a qual desestimula a reflexão autônoma e incentiva a interpretação de textos. O resultado é o surgimento entre nós de um novo tipo de estrangeirado: aquele que, mesmo sem ser diplomata, viveu e estudou no exterior, mas que retornou como comentador de textos que não se preocupa com a realidade à sua volta. Poderíamos chamá-lo de estrangeirado exegeta. Não foi à toa que Paulo Arantes, no seu conhecido livro Um departamento francês de ultramar, afirmou que, no Brasil, ensinamos o aluno a fechar-se em si mesmo e a interpretar textos filosóficos. Não foi à toa também que Oswaldo Porchat, em seu famoso Discurso aos estudantes, denunciou o fato de que ensinamos história da filosofia e não filosofia propriamente dita.

Em virtude dos aspectos apresentados acima, a nossa prática filosófica tem sido marcada por uma série de cacoetes acadêmicos, como, p. ex.: a redação de artigos que, muitas vezes, não passam de trabalhos escolares bem escritos e sem originalidade, por parte de 
muitos de nossos pesquisadores; a aceitação acrítica de problemas filosóficos europeus e norte-americanos, como se fossem também nossos; a defesa da universalidade da filosofia, mas apenas em seu formato europeu e norte-americano, que não possui necessariamente essa característica; o uso inconsciente sobretudo de anglicismos, como fenomenalismo, representacionalismo, etc. Esses cacoetes são complementados por alguns preconceitos voltados contra a filosofia brasileira, como, p. ex.: a dúvida sobre a existência dela, representada pela conhecida expressão filosofia do/no Brasil; a invisibilidade dos filósofos brasileiros perante a comunidade filosófica do país, motivada pelo pouco interesse nesse assunto e pelo forte desprezo pelos conterrâneos que tiveram a ousadia de criar alguma coisa original entre nós.

Os preconceitos acima foram motivados pelos primeiros historiadores da filosofia brasileira, caracterizados pela adoção de posturas tendenciosas na análise dos nossos autores e pelo desrespeito a toda elaboração pessoal. Silvio Romero iniciou o processo, com suas críticas acerbas a alguns autores do sec. XIX, Tobias Barreto deu seguimento, ao afirmar que o Brasil não tem “cabeça filosófica”, Cruz Costa e Leonel Franca, por sua vez, encerraram o processo com chave de ouro, o primeiro ridicularizando os antecessores como "filosofantes", “diletantes" e "filoneístas", e o segundo desqualificando os antecessores como "autodidatas".

Em virtude desses equívocos, acabamos desenvolvendo uma visão deformada da história da filosofia brasileira e seu significado. Desse modo, no que diz respeito à questão ligada à expressão filosofia do/no Brasil, achamos que vale a pena observar que estamos repetindo aqui, com atraso, um debate travado entre Salazar Bondy e Leopoldo Zea, no final da década de 1960 e nos inícios da década de 1970, a respeito da existência ou não de uma filosofia latino-americana. Para o primeiro, em virtude do imperialismo, não há filosofia na América Latina, se a entendermos como raciocínio sistemático enraizado na sociedade. Culturas defectivas, como as latino-americanas, acabam tomando obras inautênticas por obras filosóficas genuínas. Para Leopoldo Zea, em contraposição, a filosofia não assume apenas a estrutura acadêmica em que Bondy se baseia, mas envolve tentativas de dar sentido à vida em diferentes formas. Negar o passado porque ele é defectivo constitui uma fuga da realidade. ${ }^{2} \mathrm{O}$ debate acima ressurgiu entre nós porque alguns autores, seguindo o espírito de Bondy, pensam que só há filosofia quando ela corresponde aos padrões acadêmicos instaurados pelo etnocentrismo europeu. Em oposição, outros autores, seguindo o espírito de Zea, assumem um

\footnotetext{
${ }^{2}$ Ver Bondy (1968); Zea (1969). Para uma descrição e avaliação do debate, ver Schutte (1993, p. 73-108).
} 
conceito mais flexível de filosofia, deixando de lado a exigência de enquadrá-la nos padrões etnocêntricos europeus.

No que diz respeito à invisibilidade dos filósofos brasileiros em seu próprio país, os preconceitos criados pelos primeiros historiadores da nossa filosofia levaram uma parcela significativa dos estudiosos do assunto ligados à ANPOF a afirmar, sem o devido conhecimento de causa, que ainda não surgiu entre nós alguém merecedor do título de filósofo. Essa postura os leva a afirmar injustamente que pensadores independentes como os já listados acima não foram ou não são filósofos em sentido pleno. Teremos de aguardar pacientemente pela chegada do nosso primeiro Aristóteles. Isso desmotivou fortemente o estudo desses e de outros pensadores, criando uma situação paradoxal em que os melhores estudos a respeito deles foram feitos por pesquisadores estrangeiros, como no caso da tese de Fred Sturm sobre Farias Brito ou do livro de Charlotte Hammond Matthews sobre Nísia Floresta. $^{3}$

Um outro fato que agravou esses preconceitos foi a cisão ideológica pela qual a comunidade filosófica brasileira passou na década de 1930. Nessa ocasião, os pensadores brasileiros de esquerda, em geral docentes do Departamento de Filosofia da USP, seguindo seus pressupostos teóricos, não admitiam a existência de uma filosofia nacional. Já os pensadores de direita, em geral ligados à Escola de Direito também da USP, sob a liderança de Miguel Reale, seguindo seus pressupostos teóricos, admitiam a existência de uma filosofia nacional. Isso provocou uma ruptura na comunidade filosófica brasileira que apresenta sequelas até os dias de hoje. As diferentes orientações pedagógicas que separam as instituições ligadas à ANPOF daquelas ligadas à Sociedade Brasileira de Filosofia, antes mencionadas, constituem uma ilustração desse fato.

Como também vimos, apesar de pertencerem a tendências diferentes, esses dois grupos têm em comum a prática do comentário de textos. No caso da ANPOF, a justificativa inicial para o estímulo à exegese foi a de que, como ainda não temos suficiente preparo intelectual, deveríamos nos exercitar no comentário acadêmico de textos filosóficos até atingirmos uma maturidade intelectual que nos libertasse do filoneísmo, do diletantismo e do autodidatismo que marcaram os pensadores do passado. Acontece que já estamos praticando esse comentário de textos há mais de setenta e sete anos e até agora ninguém teve a coragem de anunciar que já passou a hora de atingir essa maturidade. A pergunta que se coloca no momento é a seguinte: até quando deveremos permanecer nessa situação, estimulando o

\footnotetext{
${ }^{3}$ Ver Sturm (1961); Sturm (1962, p. 85-106) e Matthews (2012).
} 
comentário de textos e desconsiderando as elaborações pessoais? Devemos nos esforçar para libertar-nos dessa forma alienada de fazer filosofia ou dedicar-nos ao comentário perpétuo de textos?

\section{AVAliAÇÃo DESSA SITUAÇÃo E PROPOSTA DE SUPERAÇÃo PELA VIA DESCOLONIAL}

Uma maneira nova e provavelmente mais eficiente de avaliar a nossa situação é oferecida pelo pensamento descolonial. Para levá-la adiante, é preciso que nos lembremos do fato de que nossa pedagogia filosófica reflete, em última análise, a nossa história de país colonizado por Portugal. Essa história nos brindou com uma autoimagem negativa que nos assombra até hoje. E, se quisermos avançar de maneira mais autêntica, temos de repensar nossa autoimagem não com base nos critérios europeus coloniais que a originaram, mas sim em critérios descoloniais mais apropriados à nossa realidade.

Para que tenhamos uma ideia mais clara da via do pensamento descolonial, tomaremos como exemplo de análise o famoso marco de pedra que os portugueses assentaram nas terras do Brasil por ocasião da chegada da frota de Cabral ao país. De acordo com a visão tradicional, esse marco teve o seguinte significado. Em primeiro lugar, novas terras a sudoeste de Portugal foram descobertas pelos lusitanos. Em segundo, eles tomaram posse dessas novas terras em nome do rei de Portugal, colocando-as sob a jurisdição do direito europeu. Em terceiro, os povos analfabetos que ocupavam essas terras tiveram o benefício de sair da préhistória e ingressar na história. Em quarto, estava iniciado o processo de colonização das novas terras, envolvendo não apenas a árdua tarefa de civilizar cristãmente os selvagens que as habitavam, mas também a vantagem da compensação econômica decorrente dessa mesma tarefa.

Do ponto de vista descolonial, o marco de pedra teve um significado muito diferente. $\mathrm{O}$ ato de assentá-lo, tomando posse das novas terras em nome do rei de Portugal diante dos verdadeiros proprietários delas, que ingênua e curiosamente contemplavam a cerimônia, sem ter noção do que estava se passando, é emblemático nesse sentido. Em primeiro lugar, o que de fato ocorreu não foi o "descobrimento" de novas terras por parte dos portugueses, mas sim um encontro deles com outros povos que já viviam nelas e que já as tinham "descoberto" por conta própria há muito tempo. 
Em segundo lugar, com o marco de pedra, os portugueses iniciaram o processo de colonização do espaço, estabelecendo uma diferença fundamental entre o lugar ocupado pela metrópole e o lugar ocupado pelas novas terras. Parodiando Descartes, diríamos que uma pessoa localizada na metrópole poderia afirmar: penso aqui, logo existo. Em contrapartida, uma pessoa localizada na colônia teria de dizer: penso aqui, logo não existo. Não apenas isso, porém. A colonização do espaço significou também a usurpação das terras dos indígenas, seus verdadeiros proprietários que não tinham consciência do que estava se passando; um aviso aos eventuais usurpadores (franceses, ingleses, espanhóis, holandeses) de que aquelas terras já tinham sido usurpadas; uma contribuição para a divisão do mapa mundi em duas partes, uma civilizada e outra por civilizar.

Em terceiro lugar, os portugueses iniciaram também o processo de colonização do tempo, estabelecendo uma diferença entre o grau de desenvolvimento por eles alcançado e o grau de desenvolvimento dos habitantes das novas terras. Aqui, apesar de estarem entrando em contato com contemporâneos seus, os portugueses estabeleceram uma linha evolutiva que partia dos indígenas e chegava até eles. É como se, ignorando a diversidade das evoluções culturais possíveis, os lusitanos vissem a si próprios como o ponto de chegada da evolução pela qual os indígenas iriam passar. Em síntese, a colonização do tempo significou uma distinção entre história madura (do europeu) e infância histórica (do indígena); a saída da colônia da pré-história - só transmissão oral da tradição - e seu ingresso na história - registro e transmissão escrita da tradição,- tais como entendidas pelo colonizador; a localização dogmática da história do indígena e da colônia no início de uma evolução cujo ponto de chegada é a sociedade da metrópole.

Em quarto lugar, e em consonância com as colonizações anteriores, o marco também significou o início da colonização do pensamento dos habitantes das novas terras. Se, por um lado, do ponto de vista tradicional, o marco representou a subordinação das novas terras à jurisdição europeia, por outro, do ponto de vista descolonial, ele representou a imposição ilegal dessa jurisdição aos habitantes locais, que não foram sequer consultados a respeito e que dali em diante só poderiam agir e sobretudo pensar de acordo com as categorias dessa mesma jurisdição. A missa solene rezada na ocasião contribuiu para o processo de colonização do pensamento, ao impor o cristianismo como única religião verdadeira nas novas terras. E a carta de Caminha, contemporânea do marco, também ilustra o processo de colonização do pensamento, ao avaliar as novas terras e seus habitantes do ponto de vista das categorias europeias. O maior problema da colonização do pensamento está em que a visão 
etnocêntrica do colonizador aos poucos foi incorporada pelo colonizado, que passou a ver a si próprio a partir dela. Desse modo, a colonização do pensamento significou a aplicação indevida de critérios europeus na avaliação das sociedades que se formavam. E talvez a consequência mais perversa desse processo tenha sido o surgimento do problema de estabelecer a identidade do colonizado com base nos critérios etnocêntricos estabelecidos pelo colonizador. Enquanto não percebermos que, em virtude do pacto colonial, jamais teremos uma identidade capaz de satisfazer a esses critérios etnocêntricos, também não perceberemos que nossa identidade só pode ser obtida com base em outros critérios, de preferência descoloniais, por serem mais adequados à compreensão da nossa realidade.

As nossas análises acima se inspiraram nas doutrinas de Walter Mignolo, um dos grandes representantes do pensamento descolonial. Ele é um argentino, especialista em semiótica, que estudou na École des Hautes Études e atua como professor titular na Duke University. Em suas pesquisas, trabalhou diversos aspectos do mundo moderno que ainda permanece colonial, explorando conceitos como pensamento descolonial, geopolítica do conhecimento, transmodernidade, pensamento de fronteira e hermenêutica pluritópica. Mignolo tem por objetivo ir além de Mangabeira Unger. Esse último pretende romper o código que baseia a unidade do pensamento liberal, enquanto Mignolo pretende não apenas romper esse código liberal, mas também quebrar o código ocidental, baseado na lógica da colonialidade e na retórica da modernidade. A nova hermenêutica que ele propõe e chama de pluritópica põe em questão a posição e a homogeneidade do sujeito do ato de compreensão. Ela envolve um conceito interativo de conhecimento e compreensão que reflete o próprio processo de construir o objeto a ser conhecido. A abordagem pluritópica não enfatiza a relatividade cultural nem o multiculturalismo, mas sim os interesses humanos no ato de contar uma estória como intervenção política. É a política de decretar e de construir lugares de enunciação que está em questão, ao invés da diversidade de representações resultantes de diferenças locais ao contar estórias ou construir teorias. Por motivos de espaço, teremos de nos contentar apenas com essas informações genéricas sobre as ideias de Mignolo, cuja leitura recomendamos insistentemente ao leitor. ${ }^{4}$

No que segue, iremos saltar alguns séculos e concentrar a atenção sobre a colonização do pensamento aplicada à maneira como praticamos a filosofia no país hoje em dia. Com tal procedimento, podemos constatar com relativa facilidade os reflexos atuais da situação descrita no caso do marco de pedra. Ora, como a filosofia praticada aqui não satisfaz aos

\footnotetext{
${ }^{4}$ Ver Mignolo (2003); Mignolo (2000); Mignolo (2011) e Mignolo (2005).
} 
critérios etnocêntricos europeus, ela não é considerada propriamente filosofia. Os nossos pensadores que se ocuparam dela não são propriamente filósofos, mas, no máximo, “filosofantes", como afirma Cruz Costa, um dos maiores representantes do nosso pensamento colonizado. E, por causa disso, até hoje ainda nos ocupamos com a discussão ociosa envolvendo a escolha entre a filosofia do Brasil e a filosofia no Brasil. Aqueles que optam pela segunda alternativa costumam usar como argumento que a filosofia é universal e que, portanto, uma "filosofia brasileira" seria uma contradição em termos. Mas parecem esquecerse de que a própria tese da universalidade da filosofia possui origem europeia e constitui um fenômeno historicamente localizado que não pode ser separado de suas circunstâncias específicas, que incluem a dimensão da cultura nacional. Talvez o mais correto seria dizermos que uma doutrina filosófica geralmente é viável no seu contexto histórico-cultural, mas dificilmente válida em quaisquer outras circunstâncias histórico-culturais. Parafraseando e adaptando Carnap, pensamos que seria melhor adotar aqui um princípio de tolerância filosófica, segundo o qual uma perspectiva filosófica deve ser julgada não em função de critérios europeus etnocêntricos, mas sim em função de critérios ligados ao contexto específico em que surgiu a perspectiva em questão. Nesse ponto, achamos conveniente lembrar que não estamos defendendo um relativismo extremado, que não nos levaria a lugar algum. O que estamos propondo é a adoção de um princípio de relatividade, segundo o qual as nossas relações com o mundo e com os outros são causais e podem assumir múltiplas formas, levando assim à elaboração de múltiplos artefatos culturais que também podem assumir múltiplas formas. As diversas filosofias das diversas épocas históricas corresponderiam às diversas formas de um desses artefatos culturais, ao qual costumamos chamar de filosofia. Isso significa que existem de fato filosofias nacionais e, em alguns casos, até mesmo filosofias nacionalistas vestidas de uma roupagem aparentemente universal, como no caso de Fichte, por exemplo. ${ }^{5}$

Esperamos que as considerações acima ajudem a mostrar com mais clareza as providências que teremos de tomar para superar essa situação equivocada através do pensamento descolonial. Entre tais providências, destacam-se as seguintes. Em primeiro lugar, será necessário reavaliar a historiografia da filosofia brasileira, mostrando suas limitações e seus preconceitos gerados por um pensamento colonizado. Para tanto,

\footnotetext{
${ }^{5}$ Sobre o conceito de filosofia e as questões da sua universalidade e da sua nacionalidade, acima discutidos, estamos apresentando aqui apenas as conclusões a que chegamos em nosso artigo $O$ que é filosofia brasileira, a ser publicado na revista Annales, da Faculdade Jesuíta de Filosofia e Teologia. Remetemos o leitor a esse artigo para uma justificativa mais adequada dessas conclusões.
} 
precisaremos de uma concepção mais flexível de filosofia, que revele com clareza o que foi efetivamente produzido em nosso passado sob a forma de reflexão filosófica sobre nossa realidade, mesmo que essa reflexão não esteja dentro dos padrões acadêmicos estabelecidos pelo etnocentrismo europeu. Essa noção mais flexível, pouco contaminada por esse último, deve ser suficiente para podermos entender melhor a nossa prática no domínio filosófico. Sugerimos que a filosofia não seja entendida exclusivamente como uma prática acadêmica rigorosa, mas como um conjunto de práticas pluriformes, cujos resultados podem ser poemas, diálogos, atitudes de vida, ensaios, tratados, obras acadêmicas, etc. Essa prática está sempre ligada a um contexto histórico determinado e reflete isso em seus posicionamentos. Ela é melhor explicável por semelhanças de família, uma noção de origem europeia, é verdade, mas suficientemente flexível para ser liberada de seu contexto etnocêntrico e adaptada a circunstâncias não europeias. Nessa perspectiva, a filosofia não se identifica exclusivamente com a atividade desenvolvida sob essa denominação na Europa e nos EUA. Com base nisso, precisamos revelar o que foi produzido aqui apesar de não se enquadrar nos padrões etnocêntricos. Isso nos permitirá reconhecer, nas avaliações ideológicas de nossos primeiros historiadores, os argumentos ad hominem como "autodidatismo", "diletantismo", "bacharelismo", "sibaritismo intelectual" e "filloneísmo", que foram dogmaticamente lançados contra os nossos pensadores. E nos permitirá reconhecer também, pelo real e cuidadoso confronto com a produção de autores brasileiros voltados para o assunto, aqueles casos em que existe pensamento autônomo e originalidade, mesmo se estiverem fora dos padrões etnocêntricos europeus.

Em segundo lugar, e em estreita conexão com a revisão da historiografia da filosofia brasileira, será preciso eliminar a invisibilidade que, principalmente na comunidade da ANPOF, impede o reconhecimento de pensadores brasileiros mais originais. Essa invisibilidade deverá ser combatida pela leitura mais cuidadosa e respeitosa acima mencionada, permitindo estudos mais detalhados e menos preconceituosos dos nossos pensadores mais significativos. Já apresentamos acima uma lista com os nomes de alguns deles, mas há vários outros também merecedores de atenção. Esse procedimento irá deixar claro que essa é a maneira adequada para localizar a produção filosófica mais autêntica entre nós.

Essas duas providências poderão constituir um estímulo a um outro aspecto importante para o desenvolvimento da atividade filosófica preocupada com a realidade nacional: a produção de obras autônomas e originais. Isso pode ser feito antropofagicamente, adaptando 
ao nosso contexto até mesmo as contribuições de autores de outras culturas e outras épocas. Isso deverá mostrar, aos poucos, que boa parte da nossa produção filosófica, principalmente a de caráter exegético, não é significativa nem para a filosofia brasileira nem para as filosofias europeia e norte-americana.

Para encerrar, uma vez que estamos falando de um tipo novo de pensamento, cabe aqui a pergunta sobre qual seria a escrita correta para designá-lo: decolonial ou descolonial? Os primeiros trabalhos sobre o assunto foram escritos em inglês, de modo que a expressão usada foi decolonial. As primeiras traduções desses trabalhos para o português e o espanhol utilizaram a mesma grafia. Acontece que, do ponto de vista tanto da ortografia portuguesa como da espanhola, a forma correta seria descolonial, uma vez que o prefixo de sem o $s$ está mais de acordo com a ortografia inglesa e constitui um anglicismo. Alguns autores dizem que o uso de decolonial constitui um galicismo, talvez porque a origem primeira da palavra parece ter vindo do francês décolonial. Mas, tendo em vista que o termo foi usado inicialmente em inglês para designar a nova teoria que surgiu nos EUA, o mais correto seria usar anglicismo. De qualquer modo, ao menos no Brasil, a questão de saber qual seria a escrita correta ainda não está decidida, com posições favoráveis às duas grafias. Luciana Ballestrini, p. ex., em entrevista concedida à Revista do Instituto Humanitas Unisinos - IHU on-line - opta por decolonial, argumentando que essa expressão não deve ser confundida com descolonização. Essa última indica a superação do colonialismo, enquanto a ideia de decolonialidade indica exatamente o contrário e procura transcender a colonialidade, a face obscura da modernidade, que ainda opera nos dias de hoje segundo um padrão mundial de poder. ${ }^{6}$ Por razões análogas, Colaço e Damázio defendem o uso do termo decolonial ao invés de descolonial. De acordo com elas, a questão foi tratada em inglês usando-se o termo decoloniality, sobre o qual existe um consenso entre os autores que escreveram nessa mesma língua. Colaço \& Damázio preferem o termo decolonial, pelos mesmos motivos que Catherine Walsh. Essa última utiliza o termo decolonial, suprimindo o $s$ para marcar uma distinção com o significado de descolonizar em seu sentido clássico. Deste modo ela pretende salientar que a intenção não é desfazer o colonial ou revertê-lo, ou seja, superar o momento colonial a favor do momento pós-colonial. A intenção é provocar um posicionamento contínuo de transgredir e insurgir. O

\footnotetext{
${ }^{6}$ Ver "Para transcender a colonialidade", entrevista com a prof ${ }^{\mathrm{a}}$ Luciana Ballestrin (2013).
} 
decolonial implica, portanto, uma luta contínua. ${ }^{7}$ Outros autores favoráveis ao uso de decolonial são Ana Catarina Resende e Paulo Henrique Martins. ${ }^{8}$

Embora em menor número, temos também defensores do uso de descolonial. De acordo com Natalia Martinuzzi Castilho, o uso de tal termo ocorre principalmente nos artigos que foram traduzidos para o português por autores que veem a descolonização não como simples superação do colonialismo, mas como síntese de uma ferramenta voltada para a supressão das opressões e das estruturas geopolíticas de um mundo extremamente desigual. Embora reconheça a importância do debate entre decolonialidade e descolonialidade, Castilho pensa que a utilização desse último termo é estratégica, uma vez que é necessário levar em conta de que maneira os autores vêm sendo traduzidos para o português. ${ }^{9}$ De nossa parte, também optamos pelo uso de descolonial pelos seguintes motivos. Em primeiro lugar, o fato de decolonial ser um anglicismo sugere que seu uso em português decorreu de uma tradução colonizada, que desrespeita a nossa grafia em beneficio de uma grafia estrangeira. Nessa perspectiva, o uso de decolonial como se fosse um neologismo e não um anglicismo tem o grande inconveniente de sugerir que, mesmo quando queremos exercer o pensamento descolonial, ainda estamos praticando uma forma colonizada de pensar. Ora, esse paradoxo deveria ser evitado a todo custo. Em segundo lugar, não vemos um perigo real de confusão entre descolonial e descolonização. O primeiro termo denota uma atividade crítica constante contra a colonialidade que nos afeta até os dias de hoje, que dificilmente será identificada com o processo histórico de descolonização que ocorreu no séc. XX. Além disso, contra Colaço e Damázio, podemos ver claramente que descolonial também denota alguma forma de descolonizar, embora esse último termo não seja tomado em seu sentido clássico.

\section{OBSERVAÇÕES FINAIS}

Depois de descrever a situação atual da filosofia praticada no Brasil, com base nas correntes que identificamos na nossa história marcada pela tradição ibérica, pudemos observar uma série de problemas que entravam o desenvolvimento dessa atividade entre nós, sobretudo nas instituições ligadas à ANPOF. Dentre esses problemas, destacamos o desinteresse pela filosofia brasileira, a invisibilidade dos nossos autores mais importantes e a criação, no país, de uma verdadeira comunidade de desconversação. Isso trouxe consequências maléficas para

\footnotetext{
${ }^{7}$ Ver Colaço; Damázio (2012, nota de rodapé, p. 7-8). Ver também Walsh (2009, p. 14-15, nota de rodapé).

${ }^{8}$ Ver Resende (2014, p. 52-53, nota de rodapé); Martins (2014, p. 22-41, p. 23, nota de rodapé).

${ }^{9}$ Castilho (2013, p. 12-13, nota de rodapé).
} 
o ensino da filosofia no país, envolvendo a graduação, o mestrado e o doutorado. Em todos esses casos, os alunos são preparados para praticar a exegese de textos clássicos, sem qualquer estímulo à autonomia do pensamento e à criação pessoal. Isso se reflete principalmente em nossas teses de doutorado, que exigem originalidade de um discente que não foi preparado para pensar por conta própria. Essa situação negativa está associada a vários cacoetes acadêmicos que proliferam em nossa comunidade filosófica, como, p. ex., a redação de artigos que não passam de trabalhos de graduação, a aceitação acrítica da filosofia estrangeira e da sua pretensa universalidade, o uso de uma terminologia contaminada por palavras estrangeiras, sobretudo no caso dos anglicismos. Daí as dúvidas quanto à existência da filosofia brasileira e a rejeição dos nossos pensadores como meros "filosofantes" destinados à invisibilidade. Procuramos mostrar que uma das causas disso está nos primeiros historiadores da filosofia brasileira, que, com base em perspectivas fortemente ideológicas, foram responsáveis por avaliações excessivamente negativas dos nossos pensadores. Procuramos mostrar também que, em virtude desses fatores, estamos revivendo atualmente conflitos ideológicos que já ocorreram entre nós e na filosofia latino-americana no século passado.

Para evitar que, depois de tanto tempo dedicados ao comentário de textos, acabemos nos dedicando apenas à exegese perpétua, mostramos a opção do pensamento descolonial como uma possível saída dessa situação. Tomamos como exemplo o conhecido marco de pedra que estabeleceu o início da colonização do Brasil. Através da análise descolonial dele, inspirada em algumas ideias de Walter Mignolo, revelamos como ele significou a colonização do espaço, a colonização do tempo e a colonização do pensamento. Tentamos mostrar que o pensamento colonizado é responsável nos dias de hoje pela situação em que se encontra a filosofia e propusemos, para superar tal situação, um conceito mais flexível de filosofia, bem como um princípio de tolerância filosófica, capaz de nos auxiliar no desmascaramento da tese da universalidade da filosofia europeia. Com isso, pudemos indicar as providências a serem tomadas para praticarmos uma filosofia mais autônoma e voltada para a nossa realidade: a revisão da historiografia da filosofia brasileira e a eliminação da invisibilidade dos nossos pensadores. Acreditamos que isso acabará estimulando o diálogo e a reflexão pessoal entre nós, com o consequente abandono do comentário perpétuo. Por fim, tendo em vista que um bom número de autores usa atualmente o termo decolonial, procuramos mostrar que, no fundo, isso envolve um anglicismo disfarçado em neologismo, justificando assim nossa opção pelo termo descolonial. 


\section{REFERÊNCIAS}

BALLESTRIN, Luciana. Para transcender a colonialidade. Entrevista. IHU on-line, edição 431, 04 de novembro de 2013. Disponível em http://www.ihuonline.unisinos.br/artigo/5258luciana-ballestrin. Acesso em 15/nov./2018.

BONDY, Salazar. Existe una filosofía de nuestra América? Mexico: Siglo XXI, 1968.

CASTILHO, Natalia Martinuzzi. Pensamento descolonial e teoria crítica dos direitos humanos na América Latina: um diálogo a partir da obra de Joauín Herrera Flores. São Leopoldo: Unisinos, 2013. Dissertação [mestrado].

COLAÇO, Thais Luzia; DAMÁZIO, Eloise da Silveira Petter. Novas perspectivas para a antropologia jurídica na América Latina: o direito e o pensamento decolonial. Florianópolis: Funjab; UFSC PPGD, Capes, 2012.

MARTINS, Paulo Henrique. O ensaio sobre o dom de Marcel Mauss: um texto pioneiro da crítica decolonial. Sociologias, Porto Alegre, v. 16, n. 36, Ag 2014, p. 22-41.

MATTHEWS, Ch. Hammond. Gender, race and patriotism in the works of Nísia Floresta. Woodbridge: Tamesis, 2012.

MENDIETA, Eduardo (ed.). Latin American philosophy. Currents, issues, debates. Bloomington: Indiana Un. Press, 2003.

MIGNOLO, W. Local histories/global designs. Coloniality, subaltern knowledges, and border thinking. Princeton, N. Jersey: Princeton Un. Press, 2000.

MIGNOLO, W. The darker side of the Renaissance. Litteracy, territoriality, and colonization. 2 ed. Ann Arbor: Un. of Michigan Press, 2003.

MIGNOLO, W. The darker side of Western Modernity. Global futures, decolonial options. Durham \& London: Duke Un. Press, 2011.

MIGNOLO, W. The idia of Latin America. Oxford: Blackwell Publishing, 2005.

MORAÑA, Mabel; DUSSEL, Enrique; JÁUREGUI, Carlos (eds.). Coloniality at large. Latin America and the postcolonial debate. Durham \& London: Duke Un. Press, 2008.

RESENDE, Ana Catarina Zema de. Direitos e autonomia indígena no Brasil (1960-2010): uma análise histórica à luz da teoria do sistema-mundo e do pensamento decolonial. Brasília: UnB, Tese [doutorado], 2014.

RODRÍGUEZ, Ileana (ed.). Trhe Latin American Subaltern Studies Reader. Durham \& London: Duke Un. Press, 2001.

SCHUTTE, Ofelia. Philosophy and the problem of cultural identity: from Ramos to Salazar Bondy. In: SCHUTTE, Ofelia. Cultural identity and social liberation in Latin American thought. Albany: State Un. of N. York Press, 1993, p. 73-108. 
STURM, F. G. Existence in search of essence: Farias Brito's philosophy of spirit. Dissertation. N. York: Columbia Un., 1961.

STURM, F. G. O significado atual de Farias Brito. In: Instituto Brasileiro de Filosofia. Anais do IV Congresso Nacional de Filosofia. São Paulo/Fortaleza: Un. Ceará, 1962, p. 85-106.

WALSH, Catherine. Interculturalidad, estado, sociedade: luchas (de)coloniales de nuestra época. Quito-Equador: Universidade Andina Simón Bolívar/Ediciones Abya-Yala, 2009.

ZEA, Leopoldo. La filosofía americana como filosofía sin más. Mexico: Siglo XXI, 1969. 